\title{
Set size and impression certainty: Cue vs. extremity explanations
}

\author{
ALDORA G. LEE \\ Washington State University, Pullman, Washington 99163 \\ and \\ THOMAS M. OSTROM \\ Ohio State University, Columbus, Ohio 49210
}

\begin{abstract}
Impression certainty is higher when the impression is based on a large compared to a small amount of information. Because set size, impression extremity, and certainty have been completely confounded in past research, it has been impossible to determine whether the certainty results have been due to the direct cue effects of set size or to the extremity of the overall impression. Extremity effects are shown to significantly affect certainty when set size and semantic content are held constant.
\end{abstract}

As the number of isovalent traits increases in an impression formation task, the impression rating becomes more polarized and the certainty or confidence regarding such judgments increases. These set size effects have been well documented in the research literature (Sloan \& Ostrom, 1974).

There are several possible reasons why certainty increases with set size. The number of items in the set may be used as an informational cue when people make ratings of subjective certainty (Brewer, 1968; Manis, Gleason, \& Dawes, 1966). Decisions based on a large amount of information may be seen as more accurate, and therefore expressed with greater certainty, than decisions based on a small amount of information.

A second possibility is that the increases in subjective certainty produced by increases in set size are mediated by the extremity of the prior favorability ratings, a view consistent with that expressed by Anderson (1968a). Typically, subjects first make a favorability rating and then are asked to indicate their confidence in it. Since set size increases the extremity of the favorability rating, increases in the certainty rating may derive solely from impression extremity.

The effects of set size, judgment extremity, and certainty have been completely confounded in the previous research on set size effects (e.g., Chalmers, 1971; Posavac \& McKillip, 1972; Posavac \& Pasko, 1971; Levy, Note 1; Radke, Note 2). Consequently, it has not been possible to establish whether certainty ratings increase because set size acts directly as an informational cue or because the stimulus set receives a more extreme favorability rating. One approach to

The research was supported by NSF Grant GS-38604. Facilities for data analysis were provided by the Computer Centers at Ohio State University and Washington State University. Requests for reprints should be sent to Thomas M. Ostrom, Social Psychology, 404C West 17th Avenue, Columbus, Ohio 43210. separating these two interpretations would be to vary judgmental extremity while holding set size constant. If the effect of set size on certainty ratings is solely due to set size acting as an informational cue, variations in set extremity should have no effect. Alternatively, set extremity should have a direct effect on certainty under the extremity interpretation.

Reanalysis of data presented by Weiss (1963) supported the view that certainty increases as judgmental extremity increases $(r=.72)$, where judgmental extremity was varied by presenting moderate vs. extreme items of information and set size was held constant. Unfortunately, this method of varying judgmental extremity also results in variation in the semantic ambiguity of the information item (Deese, 1965). It is impossible to determine whether greater confidence in ratings of extreme items was due to their extremity or lower ambiguity of semantic content. In set size research, semantic content is experimentally held constant while set size varies.

The present experiment provides an alternative test of the extremity interpretation that allows both set size and semantic content to be held constant. Variation in the favorability of context traits has a direct effect on the favorability ratings of a test trait when both context and test traits are presented as describing a single person (Kaplan, 1974). As context set size becomes larger, its effect on the extremity of test trait ratings increases (Kaplan, 1971). By asking subjects to rate their certainty in the favorability ratings they assign these test traits, it is possible to determine the effects of variation in judgmental extremity on subjective certainty while holding set size and semantic content constant.

\section{METHOD}

A 2 by 2 by 3 within-subjects factorial design was employed. The 
independent variables were two levels of test trait likableness (positive and negative), contexts that were either isovalent (the same valence as the test trait) or contravalent (opposite in valence to the test trait), and three levels of context trait (zero, two, or six context traits). The dependent measure was certainty ratings of test trait likableness judgment.

Person descriptions were developed using words selected from Edwards' (Note 3) normative likableness ratings of Anderson's (1988b) trait list. Based on a 7-point scale of likableness, a pool of 54 adjectives was selected with a range of 5.15 to 5.45 , and a pool of 54 adjectives was selected with a range of 2.50 to 2.89 . From each of the likableness ranges, 18 adjectives were randomly selected to be test traits, leaving the remainder as context adjectives. The mean scale value was 5.36 for the positive test traits, 5.31 for the positive context traits, 2.68 for the negative test traits, and 2.70 for the negative context traits. Latin square counterbalancing was used so that subjects would not be given person descriptions in which either test or context traits were repeated. Six 6 by 6 Latin squares were formed. In each, three positive and three negative test traits formed the rows and the six context conditions (zero, two, or six traits that were either positive or negative in scale value) formed the columns. Each subject rated a total of six stimulus sets from each of the six squares, thereby providing three observations in each cell of the 2 by 2 by 3 design. Three random orders of presentation for the stimulus sets were used when assembling the booklets.

For each stimulus person, subjects were asked to first form a general impression and then make three ratings: the favorableness of the person described on a 7-point scale, the likableness of a single test trait from the person description on a 21-point scale, and the certainty of that likableness judgment on a 7 -point scale. Five practice rating sets were followed by 36 experimental rating sets.

All subjects were fulfilling introductory psychology course experiment participation requirements. Two samples, 36 from The Ohio State University and 36 from the University of Idaho, participated in the study. Comparable patterns of significance were found for both replications, so they werc combined for all analyses.

\section{RESULTS}

\section{Overall Impression and Test Trait Ratings}

Prior to considering the certainty rating data, it was necessary to verify that the overall impression and test trait likableness ratings in this study corresponded to those previously reported in the literature (Kaplan, 1971). As set size increased for the isovalent stimulus sets, both overall impressions and test trait likability ratings became more extreme. In the contravalent case, increases in set size predictably led both ratings to become less polarized (context by set size ps $<.001)$. Table 1 gives the means for the test trait likability ratings.

\section{Certainty Ratings}

If the effect of set size is entirely due to the number of items serving directly as an informational cue, context valence and size should have no effect on the certainty ratings given the test trait, since the test trait always represents a set of Size 1 . However, if certainty is a reflection of the extremity of the test trait, certainty should increase in the isovalent condition and decrease in the contravalent condition. The data supported the extremity interpretation [context by set size $F(2,40)=6.47, p<.005$; linear component $\mathrm{p}<.001$ ]. The pattern of results (see Table 2) shows that as context leads a component trait to be rated as more extreme (Table 1), certainty ratings show a corresponding increase.

It would appear in Table 2 that the effect of the contravalent context was stronger for the positive test trait than for the negative test trait. However, this did not represent an interpretable departure from the Context by Set Size interaction, since neither the overall three-way interaction nor its linear component (both Fs $<1$ ) approached significance.

The certainty of ratings given negative test traits was less than that given positive traits $(p<.001)$. This, too, is consistent with the extremity interpretation since, as Table 1 shows, the positive test traits were more extreme (further from the scale midpoint) than the negative test traits.

\section{DISCUSSION}

The present data, while confirming that judgmental extremity directly affects subjective certainty, does not eliminate the possibility that set size also may affect certainty by acting as an informational cue. It is possible that set size operates via both routes in the usual set size study. However, it is informative to establish that the effect of set size on certainty is not solely due to its cue property.

If the cue property alone determined certainty ratings, this would support the interpretation that certainty acts as a determinant, rather than being a consequence of judgmental extremity. That is, a possible explanation of set size effects on likability ratings is that set size affects certainty, and certainty in turn determines how extreme a likability rating the subject is willing to give. The findings of this study support just the opposite direction of causality, that increasing set size leads to more extreme judgments as a result of the integration process and that greater extremity leads to greater certainty. This latter causal sequence is exactly what is proposed by integration theory (Anderson, 1974) and by meaning shift (Asch, 1946) interpretations of set size effects.

There is nothing in the present data that helps us understand why extremity affects certainty. One explanation is that judgmental variance (both within and between subjects) is necessarily reduced as judgments become more extreme when using categorical rating scales (Wyer, 1973). Reports of higher certainty for more extreme judgments may result when the judge realizes this restriction on the variance of his response (or his range of uncertainty). This interpretation was supported by the within-cell standard deviations. Although the magnitude of context-produced shifts in test trait

Table 1

Mean Likability of Test Trait

\begin{tabular}{|c|c|c|c|c|c|c|}
\hline \multirow{2}{*}{$\begin{array}{l}\text { Test } \\
\text { Trait }\end{array}$} & \multicolumn{3}{|c|}{$\begin{array}{l}\text { Isovalent Context } \\
\text { Set Size }\end{array}$} & \multicolumn{3}{|c|}{$\begin{array}{c}\text { Contravalent Context } \\
\text { Set Size }\end{array}$} \\
\hline & 1 & 3 & 7 & 1 & 3 & 7 \\
\hline $\begin{array}{l}\text { Positive } \\
\text { Negative }\end{array}$ & $\begin{array}{r}16.20 \\
7.59\end{array}$ & $\begin{array}{r}16.50 \\
6.53\end{array}$ & $\begin{array}{r}16.95 \\
6.23\end{array}$ & $\begin{array}{r}16.18 \\
8.04\end{array}$ & $\begin{array}{r}15.06 \\
7.87\end{array}$ & $\begin{array}{r}14.55 \\
8.55\end{array}$ \\
\hline
\end{tabular}

Table 2

Mean Certainty of Test Trait Rating

\begin{tabular}{cccccccc}
\hline & \multicolumn{3}{c}{$\begin{array}{c}\text { Isovalent Context } \\
\text { Set Size }\end{array}$} & & \multicolumn{3}{c}{$\begin{array}{c}\text { Contravalent Context } \\
\text { Test }\end{array}$} \\
\cline { 2 - 4 } \cline { 6 - 8 } Trait & 1 & 3 & 7 & & 1 & 3 & 7 \\
\hline Positive & 5.41 & 5.46 & 5.62 & & 5.33 & 5.12 & 5.09 \\
Negative & 4.89 & 5.14 & 5.22 & & 4.94 & 4.97 & 4.92 \\
\hline
\end{tabular}


likability ratings was not very substantial (about three units on a 21-point scale), there was a systematic effect of context on the within-cell standard deviations. All of the eight possible comparisons between isovalent and contravalent standard deviations (for each combination of context size, valence of test trait, and subject sample) showed the contravalent standard deviations to be larger.

An alternative explanation derives from considering the changes in the ambiguity in semantic meaning of the test traits that may be introduced by the isovalent and contravalent contexts. Given that each test trait has a number of associated traits (or implicational associates), context will affect which of those are linked to the test trait at the time of likability and certainty ratings (Hamilton \& Zanna, 1974; Wyer, 1974). In the isovalent context, the more remote, low-probability contravalent implicational associates would be inconsistent with the context. This would lead to a reduction in the number and likelihood of contravalent associates. Such a shift in the distribution of associates would produce a reduction in uncertainty as defined by information theory (Deese, 1965).

The decrease in certainty that accompanies an increase in contravalent context set size could result from an increase in the number and probability of contravalent implicational associates. This would lead to a more rectilinear distribution of associates, thereby increasing uncertainty.

\section{REFERENCE NOTES}

1. Levy, L. K. The effects of value, variance, and sample size on judgmental confidence and variance in social perception. Paper presented at Midwestern Psychological Association, 1965.

2. Radke, R. C. Repetition and redundancy of information in impression formation. Paper presented at Midwestern Psychological Association, 1967.

3. Edwards, J. D. Revised likableness ratings of 555 personality trait adjectives. The Ohio State University, Mimeo, 1967.

\section{REFERENCES}

Anderson, N. H. Application of a linear-serial model to a personality-impression task using serial presentation. Journal of Personality and Social Psychology, 1968, 10, 354-362. (a)

ANDERson, N. H. Likableness ratings of 555 personality-trait adjectives. Journal of Personality and Social Psychology, 1968, 9. 272-279. (b)
Anderson, N. H. Cognitive algebra: Integration theory applied to social attributions. In L. Berkowitz (Ed.), Advances in experimental social psychology. New York: Academic Press, 1974.

Asch, S. Forming impressions of personality. Journal of Abnormal and Social Psychology, 1946, 41, 258-290.

BREWER, M. B. Averaging versus summation in composite ratings of complex social stimuli. Journal of Personality and Social Psychology, 1968, 8, 20-26.

Chalmers, D. K. Repetition and order effects in attitude formation. Journal of Personality and Social Psychology, $1971,17,219-228$.

DEESE, J. The structure of association in language and thought. Baltimore, Md: Johns Hopkins Press, 1965.

Hamilton, D. L., \& Zanna, M. P. Context effects in impression formation. Journal of Personality and Social Psychology, 1974, 29, 649-654.

Kaplan, M. F. Context effects in impression formation: The weighted average versus the meaning-change formulation. Journal of Personality and Social Psychology, 1971, 19, 92-99.

KaPlaN, M. F. Context-induced shifts in personality trait evaluation. Psychological Bulletin, 1974, 81, 891-895.

Manis, M., Gleason, T. C., \& Dawes, R. M. The evaluation of complex social stimuli. Journal of Personality and Social Psychology, 1966, 3, 404-419.

Posavac, E. J., \& McKillip, J. The set size effect and confidence in reports of behavioral intentions. Psychonomic Science, 1972, 29, 94-96.

Posavak, E. J., \& PAsko, S. J. Interpersonal attraction and confidence of attraction ratings as a function of number of attitudes and attitude similarity. Psychonomic Science, 1971, 23, 433-435.

Sloan, L. R., \& Ostrom, T. M. Amount of information and interpersonal judgment. Journal of Personality and Social Fsychology, 1974, 29, 23-29.

WEISS, W. Scale judgments of triplets of opinion statements. Journal of Abnormal and Social Psychology, 1963, 66, 471-479.

WYER, R. S., JR. Category ratings as "subjective expected values": Importance for attitude formation and change. Psychological Review, 1973, 80, 446-467.

WYER, R. S., JR. Changes in meaning and halo effects in personality impression ratings. Journal of Personality and Social Psychology, 1974, 29, 829-835.

(Received for publication July 11, 1976.) 